Journal of Mathematics and Informatics

Vol. 8, 2017, 69-81

ISSN: 2349-0632 (P), 2349-0640 (online)

Published 24 August 2017

www.researchmathsci.org

DOI: http://dx.doi.org/10.22457/jmi.v8a8

Journal of

Mathematics and

Informatics

\title{
New Concepts of Interval-Valued Fuzzy Graphs with Application
}

\author{
Hossein Rashmanlou ${ }^{1}$ and Mostafa Nouri Jouybari ${ }^{2}$ \\ Department of Mathematics, Payame Noor University (PNU) \\ P.O.Box 19395-3697, Tehran, Iran \\ Email: ${ }^{1}$ rashmanlou.1987@gmail.com, ${ }^{2}$ m njoybari@ pnu.ac.ir
}

Received 19 June 2017; accepted 21 August 2017

\begin{abstract}
Concepts of graph theory are applied in many areas of computer science including image segmentation, data mining, clustering, image capturing and networking. Fuzzy graph theory is successfully used in many problems, to handle the uncertainty that occurs in graph theory. An interval-valued fuzzy graph is a generalized structure of a fuzzy graph that gives more precision, flexibility, and compatibility to a system when compared with systems that are designed using fuzzy graphs. In this paper, new concepts of irregular interval-valued fuzzy graphs such as neighbourly totally irregular intervalvalued fuzzy graph, highly irregular interval-valued fuzzy graphs and highly totally irregular interval-valued fuzzy graphs are introduced and investigated. A necessary and sufficient condition under which neighbourly irregular and highly irregular intervalvalued fuzzy graphs are equivalent is discussed.
\end{abstract}

Keywords: Interval-valued fuzzy graph, irregular interval-valued fuzzy graph.

AMS Mathematics Subject Classification (2010): 05 C78

\section{Introduction}

The origin of graph theory started with the problem of koinsber bridge, in 1735. This problem lead to the concept of Eulerian Graph. Euler studied the problem of koinsberg bridge and constructed a structure to solve the problem called Eulerian graph. In 1840, Mobius gave the idea of complete graph and bipartite graph and Kuratowski proved that they are planer by means of recreational problems. At present, graph theoretical concepts are highly utilized by computer science applications. Especially in research areas of computer science including data mining, image segmentation, clustering, image capturing networking, for example, a data structure can be designed in the form of tree which in turn utilized vertices and edges. Similarly modeling of network topologies can be done using graph concepts.

In 1975, Zadeh [40] introduced the notion of interval-valued fuzzy sets as an extension of fuzzy sets [41] in which the values of the membership degrees are intervals of numbers instead of the numbers. Interval-valued fuzzy sets provide a more adequate description of uncertainly than traditional fuzzy sets. It is therefore important to use interval-valued fuzzy sets in application, such as fuzzy control. Since interval-valued fuzzy sets are widely studied and used, we describe briefly the work of Gorzalczany on 


\section{Hossein Rashmanlou and Mostafa Nouri Jouybari}

approximate reasoning [13,14], Roy and Biswas on medical diagnosis [24] and Mendel on intelligent control [19]. In 1975, Rosenfeld [25] discussed the concept of fuzzy graphs whose basic idea was introduced by Kauffman [18] in 1973. The fuzzy relation between fuzzy sets were also considered by Rosenfeld and he developed the structure of fuzzy graphs, obtain analogs of several graph theoretical concepts. Bhattacharya [4] gave some remarks on fuzzy graphs. Mordeson and Peng [21] introduced some operations on fuzzy graphs. The complement of a fuzzy graph was defined by Mordeson [20]. Bhutani and Rosenfeld introduced the concept of M-strong fuzzy graphs in [5] and studied some of their properties. Shannon and Atanassov [39] introduced the concept of intuitionistic fuzzy relations and intuitionistic fuzzy graphs. Hongmei and Lianhua gave the definition of interval-valued graph in [15]. Recently Akram introduced the concepts of bipolar fuzzy graphs and interval-valued fuzzy graphs in [1,2,3]. Pal and Rashmanlou [23] studied irregular inteval-valued fuzzy graphs. Also, they defined antipodal intervalvalued fuzzy graphs [26], balanced interval-valued fuzzy graphs [27] and a study on bipolar fuzzy graphs [28]. Rashmanlou and Jun investigated complete interval-valued fuzzy graphs [29]. Samanta and Pal defined fuzzy tolerance graphs [32], fuzzy threshold graphs [36], fuzzy planar graphs [38], fuzzy k-competition graphs and p-competition fuzzy graphs [34], irregular bipolar fuzzy graphs [35]. Borzooei and Rashmanlou [6-12] investigated new concepts on vague graphs. In this paper, we present the concepts of neighbourly irregular interval-valued fuzzy graphs, neighbourly totally irregular interval-valued fuzzy graphs, highly irregular interval - valued fuzzy graphs, and highly totally irregular interval-valued fuzzy graphs are introduced and investigated. A necessary and sufficient condition under which neighbourly irregular and highly irregular interval-valued fuzzy graphs are equivalent is discussed.

\section{Preliminaries}

In this section, we review some elementary concepts that are necessary for this paper.

By a graph, we mean a pair $G^{*}=(V, E)$, where $V$ is the set and $E$ is a relation on $V$.

The elements of $V$ are vertices of $G^{*}$ and the elements of $E$ are edges of $G^{*}$. We write $x y \in E$ to mean $(x, y) \in E$, and if $e=x y \in E$, we say $x$ and $y$ are adjacent. Formally, given a graph $G^{*}=(V, E)$, two vertices $x, y \in V$ are said to be neighbours, or adjacent nodes, if $x y \in E$. The number of edges, the cardinality of $E$, is called the size of graph and denoted by $|E|$. The number of vertices, the cardinality of $V$, is called the order of graph and denoted by $|V|$.

A path in a graph $G^{*}$ is an alternating sequence of vertices and edges $v_{\circ}, e_{1}, v_{1}, e_{2}, \ldots, v_{n-1}, e_{n}, v_{n}$. The path graph with $n$ vertices is denoted by $P_{n}$. A path is sometime denoted by $P_{n}: v_{0} v_{1} \ldots v_{n}(n>0)$. The length of a path $P_{n}$ in $G^{*}$ is $n$. A path $P_{n}: v_{\circ} v_{1} \ldots v_{n}$ in $G^{*}$ is called a cycle is $v_{\circ}=v_{n}$ and $n \geq 3$. Note that path graph, $P_{n}$ has $n-1$ edges and can be obtain from cycle graph, $C_{n}$, by removing any edge.

The neighbourhood of a vertex $v$ in a graph $G^{*}$ is the induced subgraph of $G^{*}$ consisting of all vertices. The neighbourhood is often denoted $N(v)$. The degree $\operatorname{deg}(v)$ 
New Concepts of Interval-Valued Fuzzy Graphs with Application

of vertex $v$ is the number of edges incident on $V$ or equivalently, $\operatorname{deg}(v)=|N(v)|$. The set of neighbours called a (open) neighbourhood $N(v)$ for a vertex $v$ in a graph $G^{*}$, consists of all vertices adjacent to $v$ but not including $v$, that is $N(v)=\{u \in V \mid u v \in E\}$. When $v$ is also included, it is called a closed neighbour- hood $N[v]$, that is $N[v]=N(v) \cup\{v\}$. A regular graph is a graph where each vertex has the some number of neighbours, i.e. all the vertices have the same closed neighb-

ourhood degree. The interval - valued fuzzy set $A$ in $V$ is defined by:

$$
A=\left\{\left(x,\left[\mu_{A^{-}(x)}, \mu_{A^{+}(x)}\right]\right) \mid x \in V\right\},
$$

where $\mu_{A^{-}(x)}$ and $\mu_{A^{+}(x)}$ are fuzzy subsets of $V$ such that $\mu_{A^{-}(x)} \leq \mu_{A^{+}(x)}$ for all $x \in V$. If $G^{*}=(V, E)$ is a graph, then by an interval-valued fuzzy relation $B$ on a set $E$ we mean an interval- valued fuzzy set such that

$$
\begin{aligned}
& \mu_{B^{-}(x y)} \leq \min \left(\mu_{A^{-}(x)}, \mu_{A^{-}(y)}\right), \\
& \mu_{B^{+}(x y)} \leq \min \left(\mu_{A^{+}(x)}, \mu_{A^{+}(y)}\right),
\end{aligned}
$$

for all $x y \in E$.

\section{Interval-valued fuzzy graphs}

Definition 3.1. By an interval - valued fuzzy graph of a graph $G^{*}=(V, E)$ we mean a pair $G=(A, B)$, where $A=\left[\mu_{A^{-}}, \mu_{A^{+}}\right]$is an interval - valued fuzzy set on $V$ and $B=\left[\mu_{B^{-}}, \mu_{B^{+}}\right]$is an interval - valued fuzzy relation on $E$ such that

$$
\begin{aligned}
& \mu_{B^{-}(x y)} \leq \min \left(\mu_{A^{-}(x)}, \mu_{A^{-}(y)}\right) \\
& \mu_{B^{+}(x y)} \leq \min \left(\mu_{A^{+}(x)}, \mu_{A^{+}(y)}\right) .
\end{aligned}
$$

Throughout in this paper, $G^{*}$ is a crisp graph, and $G$ is an interval - valued fuzzy graph.

Definition 3.2. The number of vertices, the cardinality of $V$, is called the order of an interval-valued fuzzy graph $G=(A, B)$ and denoted by $|V|$ (or $O(G))$, and defined by

$$
O(G)=|V|=\sum_{x \in V} \frac{1+\mu_{A^{-}(x)}+\mu_{A^{+}(x)}}{2} .
$$

The number of edges, the cardinality of $E$, is called the size of an interval - valued fuzzy graph $G=(A, B)$ and denoted by $|E|$ (or $S(G))$, and defined by

$$
S(G)=|E|=\sum_{x y \in E} \frac{1+\mu_{B^{-}(x y)}+\mu_{B^{+}(x y)}}{2} .
$$

Definition 3.3. Let $G$ be an interval - valued fuzzy graph. The neighbourhood of a vertex $x$ in $G$ is defined by $N(x)=\left(N_{\mu}(x), N_{v}(x)\right)$, where 
Hossein Rashmanlou and Mostafa Nouri Jouybari

$$
\begin{aligned}
& N_{\mu}(x)=\left\{y \in V: \mu_{B^{-}(x y)} \leq \min \left(\mu_{A^{-}(x)}, \mu_{A^{-}(y)}\right)\right\} \text { and } \\
& N_{v}(x)=\left\{y \in V: \mu_{B^{+}(x y)} \leq \min \left(\mu_{A^{+}(x)}, \mu_{A^{+}(y)}\right)\right\} .
\end{aligned}
$$

Definition 3.4. Let $G$ be an interval - valued fuzzy graph. The neighbourhood degrees of vertex $x$ is $G$ is defined by $\operatorname{deg}(x)=\left(\operatorname{deg}_{\mu}(x), \operatorname{deg}_{v}(x)\right)$, where $\operatorname{deg}_{\mu}(x)=\sum_{y \in N(x)} \mu_{A^{-}(y)}$ and $\operatorname{deg}_{v}(x)=\sum_{y \in N(x)} \mu_{A^{+}(y)}$. Notice that $\mu_{B^{-}(x y)}>\circ, \mu_{B^{+}(x y)}>\circ$ for all $x y \in E$, and $\mu_{B^{-}(x y)}=\mu_{B^{+}(x y)}=\circ$ for all $x y \notin E$

Definition 3.5. Let $G$ be an interval - valued fuzzy graph on $G^{*}$. If there is a vertex where is adjacent to vertices with distinct neighbourhood degrees, then $G$ is called an irregular interval-valued fuzzy graph. That is, $\operatorname{deg}(x) \neq n$ foa all $x \in V$.

Example 3.6. Consider a graph $G^{*}=(V, E)$ such that $V=\left\{u_{1}, u_{2}, u_{3}\right\}$, $E=\left\{u_{1} u_{2}, u_{2} u_{3}, u_{3} u_{1}\right\}$. Let A be an interval-valued fuzzy subset of $V$ and let $B$ be an interval-valued fuzzy subset of $E \subseteq V \times V$ defined by

\begin{tabular}{|l|c|c|c|}
\hline & $u_{1}$ & $u_{2}$ & $u_{3}$ \\
\hline$\mu_{A^{-}}$ & 0.3 & 0.3 & 0.4 \\
\hline$\mu_{A^{+}}$ & 0.7 & 0.8 & 0.5 \\
\hline
\end{tabular}

\begin{tabular}{|c|c|c|c|}
\hline & $u_{1} u_{2}$ & $u_{2} u_{3}$ & $u_{3} u_{1}$ \\
\hline$\mu_{B^{-}}$ & 0.2 & 0.3 & 0.2 \\
\hline$\mu_{1} \mu_{B^{+}}$ & 0.3 & 0.4 & 0.3 \\
\hline
\end{tabular}

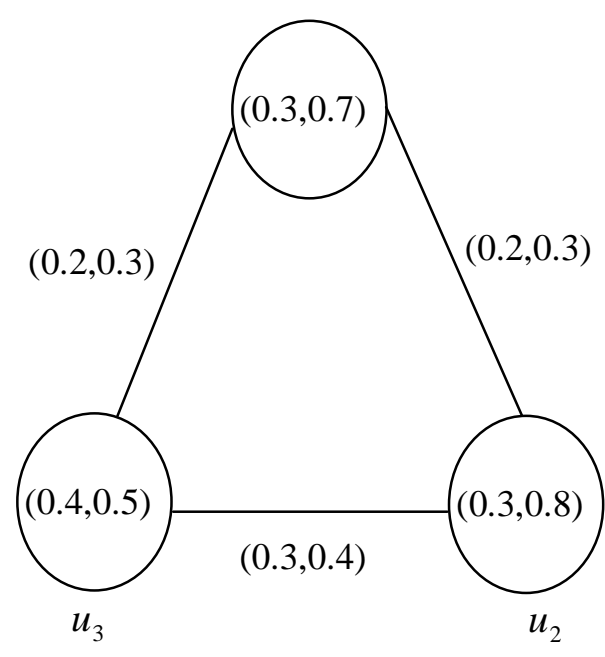

Figure 1: Interval-valued fuzzy graph $\mathrm{G}$

By routine computations, we have $\operatorname{deg}\left(u_{1}\right)=(0.7,1.3), \operatorname{deg}\left(u_{2}\right)=(0.7,1.2)$ and $\operatorname{deg}\left(u_{3}\right)=(0.6,1.5)$. It is clear that $G$ is an irregular interval- valued fuzzy graph. 
New Concepts of Interval-Valued Fuzzy Graphs with Application

Definition 3.7. Let $G$ be an interval-valued fuzzy graph. The closed neighbour-hood degree of a vertex $x$ is defined by $\operatorname{deg}[x]=\left(\operatorname{deg}_{\mu}[x], \operatorname{deg}_{\nu}[x]\right)$, where $\operatorname{deg}_{\mu}[x]=\operatorname{deg}_{\mu}(x)+\mu_{A^{-}}(x), \operatorname{deg}_{v}[x]=\operatorname{deg}_{v}(x)+\mu_{A^{+}}(x)$.

If there is a vertex which is adjacent to vertices with distinct closed neighbourhood degrees, then $G$ is called a totally irregular interval-valued fuzzy graph.

Example 3.8. Consider an interval-valued fuzzy graph $G$ such that $V=\left\{u_{1}, u_{2}, u_{3}, u_{4}, u_{5}\right\}, E=\left\{u_{1} u_{2}, u_{2} u_{3}, u_{2} u_{4}, u_{3} u_{1}, u_{3} u_{4}, u_{4} u_{1}, u_{4} u_{5}\right\}$.

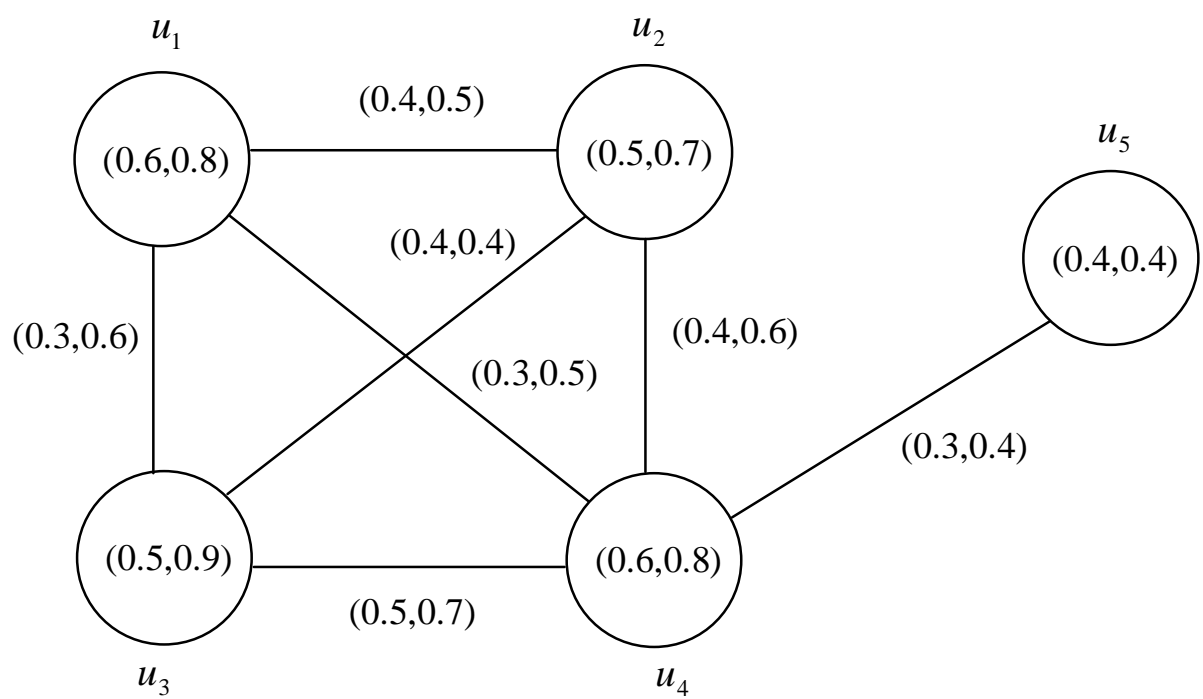

Figure 2: Totally irregular interval-valued fuzzy graph $\mathrm{G}$

By routine computations, we have $\operatorname{deg}\left[u_{1}\right]=(2.2,3.2), \operatorname{deg}\left[u_{2}\right]=(2.2,3.2)$,

$\operatorname{deg}\left[u_{3}\right]=(2.2,3.2), \operatorname{deg}\left[u_{4}\right]=(2.6,3.6), \operatorname{deg}\left[u_{5}\right]=(1,1.2)$. It is clear from calculations that $G$ is a totally irregular interval-valued fuzzy graph.

Definition 3.9. A connected interval-valued fuzzy graph $G$ is said to be a neighbourly irregular interval- valued fuzzy graph if every two adjacent vertices of $G$ have distinct open neighbourhood degree.

Example 3.10. Consider an interval-valued fuzzy graph $G$ such that $V=\left\{u_{1}, u_{2}, u_{3}, u_{4}\right\}, E=\left\{u_{1} u_{2}, u_{2} u_{3}, u_{3} u_{4}, u_{4} u_{1}\right\}$. 
Hossein Rashmanlou and Mostafa Nouri Jouybari

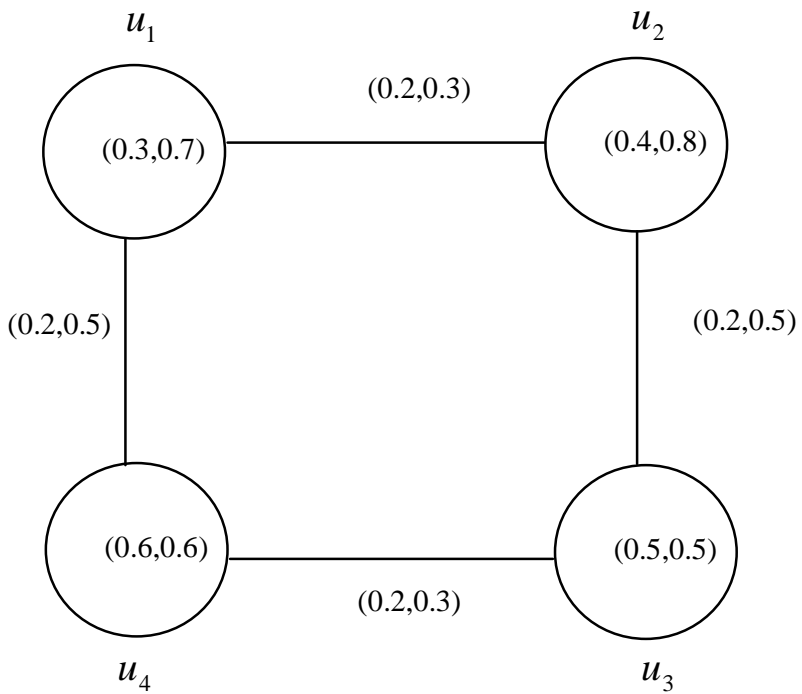

Figure 3: Neighbourly irregular interval-valued fuzzy graph $\mathrm{G}$

By routine computations, we have $\operatorname{deg}\left(u_{1}\right)=(1,1.4), \operatorname{deg}\left(u_{2}\right)=(0.8,1.2)$, $\operatorname{deg}\left(u_{3}\right)=(1,1.4)$ and $\operatorname{deg}\left(u_{4}\right)=(0.8,1.2)$. It is clear from calculations that $G$ is a neighbourly irregular interval- valued fuzzy graph.

Definition 3.11. A connected interval - valued fuzzy graph $G$ is said to be a neighbourly totally irregular interval-valued fuzzy graph if every two adjacent vertices of $G$ have distinct closed neighbourhood degree.

Example 3.12. Consider an interval-valued fuzzy graph $G$ such that $V=\left\{u_{1}, u_{2}, u_{3}, u_{4}\right\}, E=\left\{u_{1} u_{2}, u_{2} u_{3}, u_{3} u_{4}, u_{4} u_{1}\right\}$.

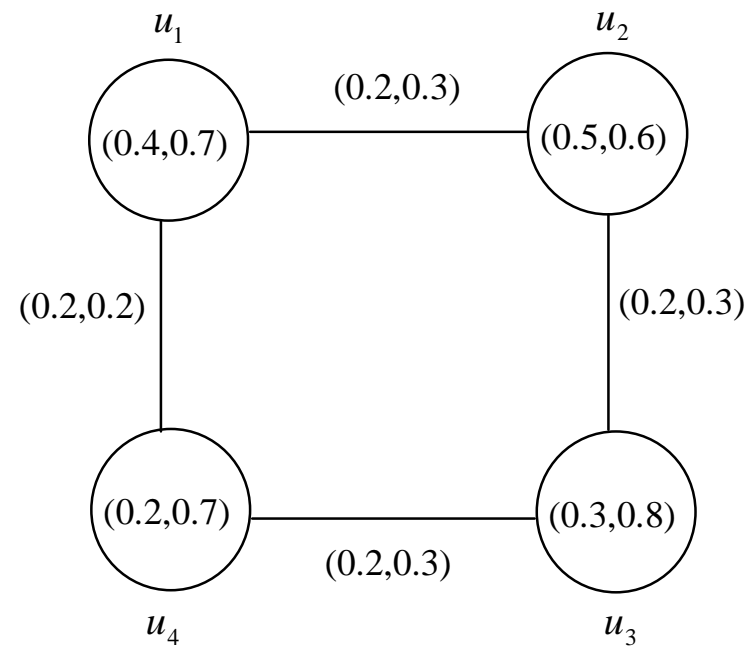

Figure 4: Neighbourly totally irregular interval-valued fuzzy graph $\mathrm{G}$ 


\section{New Concepts of Interval-Valued Fuzzy Graphs with Application}

By routine computations, we have

$\operatorname{deg}\left[u_{1}\right]=(1.1,2), \operatorname{deg}\left[u_{2}\right]=(1.2,2.1), \operatorname{deg}\left[u_{3}\right]=(1,2.1)$ and $\operatorname{deg}\left[u_{4}\right]=(0.9,2.2)$. It is easy to see that $G$ is a neighbourly totally irregular interval -valued fuzzy graph.

Definition 3.13. Let $G$ be a connected interval - valued fuzzy graph. $G$ is called a highly irregular interval- valued fuzzy graph if every vertex of $G$ is adjacent to vertices with distinct neighbourhood degrees.

Remark. A highly irregular interval-valued fuzzy graph may not be a neighbourly irregular interval - valued fuzzy graph. There is no relation between highly irregular interval-valued fuzzy graphs and neighbourly irregular interval - valued fuzzy graphs. We explain this concept with the following example.

Remark. A neighbourly irregular interval-valued fuzzy graph my not be a highly irregular interval - valued fuzzy graph.

Example 3.14. Consider an interval - valued fuzzy graph $G$ such that $V=\left\{u_{1}, u_{2}, u_{3}, u_{4}\right\}, E=\left\{u_{1} u_{2}, u_{2} u_{3}, u_{3} u_{4}, u_{4} u_{1}\right\}$.

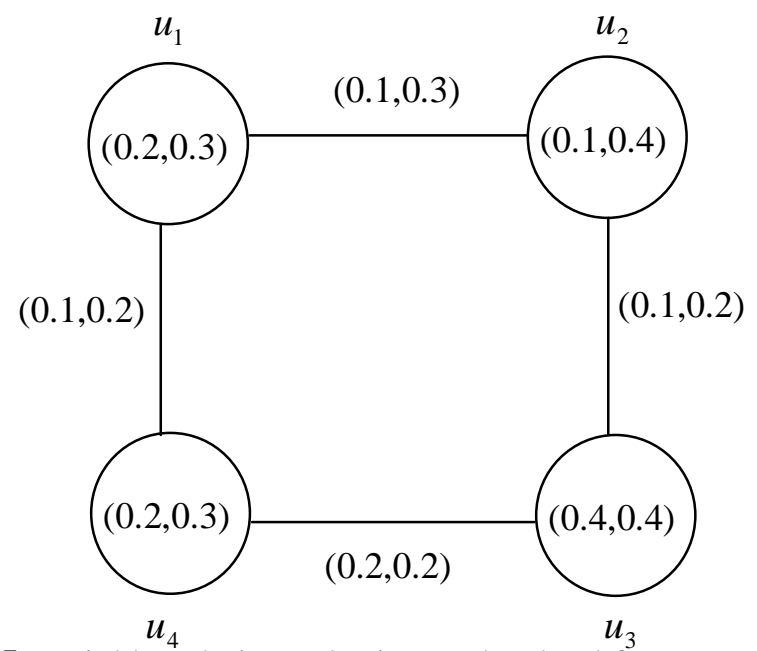

Figure 5: Neighbourly irregular interval-valued fuzzy graph G

By routine computations, we have $\operatorname{deg}\left(u_{1}\right)=(0.3,0.7), \operatorname{deg}\left(u_{2}\right)=(0.6,0.7)$, $\operatorname{deg}\left(u_{3}\right)=(0.3,0.7), \operatorname{deg}\left(u_{4}\right)=(0.6,0.7)$. We see that every two adjacent vertices have distinct neighbourhood degree. But consider a vertex $u_{2}$ which is adjacent to the vertices $u_{1}$ and $u_{3}$ has same degree, that is, $\operatorname{deg}\left(u_{1}\right)=\operatorname{deg}\left(u_{3}\right)$. Hence, $G$ is neighbourly irregular interval- valued fuzzy graph but not a highly irregular interval-valued fuzzy graph. 
Hossein Rashmanlou and Mostafa Nouri Jouybari

Theorem 3.15. Let $G$ be an interval- valued fuzzy graph. Then $G$ is highly irregular interval -valued fuzzy graph and neighbourly interval- valued fuzzy graph if and only if the neighbourhood degrees of all the vertices of $G$ are distinct.

Proof: Let $G$ be an interval - valued fuzzy graph with n-vertices $v_{1}, v_{2}, \ldots v_{n}$. Assume that $G$ is highly irregular interval-valued fuzzy graph and neighbourly interval-valued fuzzy graph.

Claim: The neighbourhood degrees of all vertices of $G$ are distinct. Let $\operatorname{deg}\left(u_{i}\right)=\left(m_{i}, n_{i}\right), i=1,2, \ldots, n$. Let the adjacent vertices of $u_{1}$ be $u_{2}, u_{3}, \ldots, u_{n}$ with neighbourhood degrees $\left(m_{2}, n_{2}\right),\left(m_{3}, n_{3}\right), \ldots,\left(m_{n}, n_{n}\right)$ respectively. Then we have $m_{2} \neq m_{3} \neq \ldots \neq m_{n}$ and $n_{2} \neq n_{3} \neq \ldots \neq n_{n}$, since $G$ is highly irregular. Also, $m_{1} \neq m_{2} \neq m_{3} \neq \ldots \neq m_{n}$ and $n_{1} \neq n_{2} \neq n_{3} \neq \ldots \neq n_{n}$, since $G$ is neighbourly irregular. Hence, the neighbourhood degree of all the vertices of $G$ are distinct.

Conversely, assume that the neighbourhood degrees of all the vertices of $G$ are distinct.

Claim: $G$ is highly irregular and neighbourly irregular interval- valued fuzzy graph.

Let $\operatorname{deg}\left(u_{i}\right)=\left(m_{i}, n_{i}\right), i=1,2, \ldots, n$. Given that $m_{1} \neq m_{2} \neq m_{3} \neq \ldots \neq m_{n}$ and $n_{1} \neq n_{2} \neq n_{3} \neq \ldots \neq n_{n}$, which implies that every two adjacent vertices have distinct neighbourhood degrees and to every vertex, the adjacent vertices have distinct neighbourhood degrees.

Theorem 3.16. An interval- valued fuzzy graph $G$ of $G^{*}$, where $G^{*}$ is a cycle with vertices 3 is neighbourly irregular and highly irregular interval- valued fuzzy graph if and only if the positive membership and negative membership value of the vertices between every pair of vertices are all distinct.

Proof: Assume that positive membership and negative membership value of the vertices are all distinct.

Claim: $G$ is neighbourly irregular and highly irregular interval-valued fuzzy graph.

Let $u_{i}, u_{j}, u_{k} \in V$. Given that, $\mu_{A^{-}}\left(u_{i}\right) \neq \mu_{A^{-}}\left(u_{j}\right) \neq \mu_{A^{-}}\left(u_{k}\right)$ and

$\mu_{A^{+}}\left(u_{i}\right) \neq \mu_{A^{+}}\left(u_{j}\right) \neq \mu_{A^{+}}\left(u_{k}\right)$, which implies that

$\sum_{x \in N(x)} \mu_{A^{-}}\left(u_{i}\right) \neq \sum_{x \in N(x)} \mu_{A^{-}}\left(u_{j}\right) \neq \sum_{x \in N(x)} \mu_{A^{-}}\left(u_{k}\right)$ and

$\sum_{x \in N(x)} \mu_{A^{+}}\left(u_{i}\right) \neq \sum_{x \in N(x)} \mu_{A^{+}}\left(u_{j}\right) \neq \sum_{x \in N(x)} \mu_{A^{+}}\left(u_{k}\right)$. That is, $\operatorname{deg}\left(u_{i}\right) \neq \operatorname{deg}\left(u_{j}\right) \neq \operatorname{deg}\left(u_{k}\right)$.

Hence, $G$ is neighbourly irregular and highly irregular interval- valued fuzzy graph.

Conversely, assume that $G$ is neighbourly irregular and highly irregular.

Claim: Positive membership and negative membership value of the vertices are all distinct. 
New Concepts of Interval-Valued Fuzzy Graphs with Application

Let $\operatorname{deg}\left(u_{i}\right)=\operatorname{deg}\left(P_{i}, Q_{i}\right), i=1,2, \ldots, n$. Suppose that Positive membership and negative value of any two vertices are same. Let $u_{1}, u_{2} \in V$. Let $\mu_{A^{-}}\left(u_{1}\right)=\mu_{A^{-}}\left(u_{2}\right)$ and $\mu_{A^{+}}\left(u_{1}\right)=\mu_{A^{+}}\left(u_{2}\right)$. Then $\operatorname{deg}\left(u_{1}\right)=\operatorname{deg}\left(u_{2}\right)$, since $G^{*}$ is cycle, which is a contradiction to the fact that $G$ is neighbourly irregular and highly irregular interval valued fuzzy graph. Hence, positive membership and negative membership value of the vertices are all distinct.

Remark. A neighbourly totally irregular interval- valued fuzzy graph may not be a neighbourly irregular interval- valued fuzzy graph.

Example 3.17. Consider an interval - valued fuzzy graph $G$ such that $V=\left\{u_{1}, u_{2}, u_{3}, u_{4}\right\}, E=\left\{u_{1} u_{2}, u_{2} u_{3}, u_{3} u_{4}, u_{4} u_{1}\right\}$.

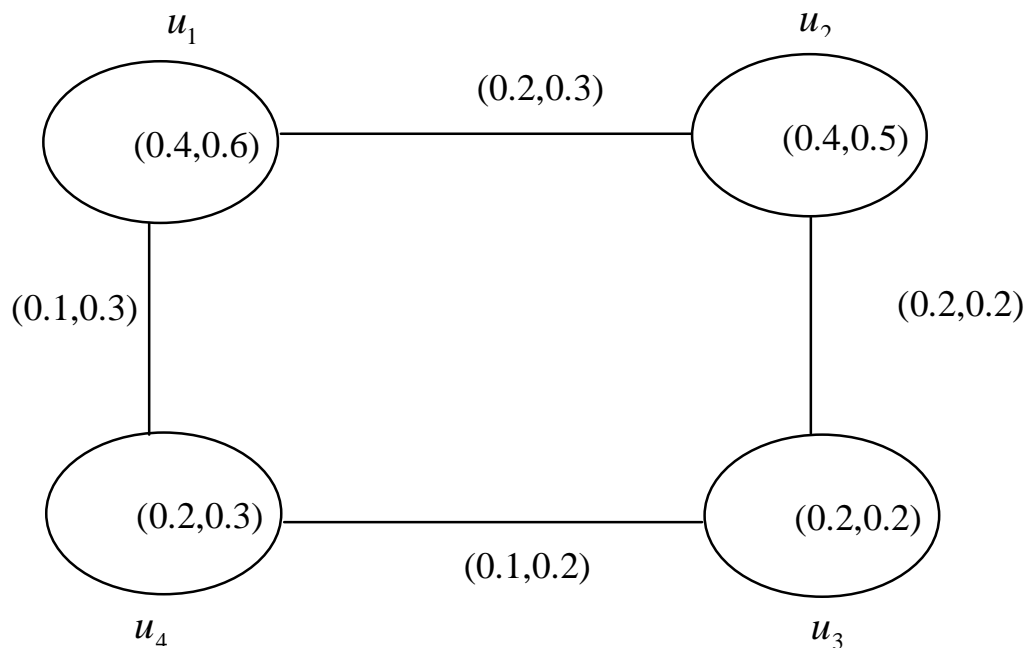

Figure 6: Neighbourly totally irregular interval-valued fuzzy graph G

By routine computations, we have $\operatorname{deg}\left[u_{1}\right]=(1,1.4), \operatorname{deg}\left[u_{2}\right]=(1,1.3)$, $\operatorname{deg}\left[u_{3}\right]=(0.8,1), \operatorname{deg}\left[u_{4}\right]=(0.8,1.1)$. But $\operatorname{deg}\left(u_{1}\right)=\operatorname{deg}\left(u_{2}\right)=\operatorname{deg}\left(u_{3}\right)=(0.6,0.8)$. Hence $G$ is neighbourly totally irregular interval-valued fuzzy graph but not a neighbourly irregular interval - valued fuzzy graph.

Proposition 3.18. Let $G$ be an interval - valued fuzzy graph. If $G$ is neighbourly irregular interval- valued fuzzy graph and $\left(\mu_{A^{-}}, \mu_{A^{+}}\right)$is a constant function, then $G$ is a neighbourly totally irregular interval-valued fuzzy graph.

Proof: Assume that $G$ is a neighbourly irregular interval-valued fuzzy graph. That is the neighbourhood degrees of every two adjacent vertices are distinct. Let $u_{i}, u_{j} \in V$, 
Hossein Rashmanlou and Mostafa Nouri Jouybari

where $u_{i}$ and $u_{j}$ are adjacent vertices with distinct neighbourhood degrees $\left(P_{1}, Q_{1}\right)$ and $\left(P_{2}, Q_{2}\right)$ respectively. That is $\operatorname{deg}\left(u_{i}\right)=\left(P_{1}, Q_{1}\right)$ and $\operatorname{deg}\left(u_{j}\right)=\left(P_{2}, Q_{2}\right)$, where $P_{1} \neq P_{2}, u_{1} \neq u_{2}$. Let us assume that $\left(\mu_{1}\left(u_{i}\right), v_{1}\left(u_{i}\right)=\left(\mu_{1}\left(u_{j}\right), v_{1}\left(u_{j}\right)=\left(c_{1}, c_{2}\right)\right.\right.$, where $c_{1}, c_{2}$ are constant and $c_{1}, c_{2} \in[\circ, 1]$. Therefore, $\operatorname{deg}_{\mu}\left[u_{i}\right]=\operatorname{deg}_{\mu}\left(u_{i}\right)+\mu_{1}\left(u_{i}\right)=P_{1}+c_{1}$ and $\operatorname{deg}_{v}\left[u_{i}\right]=\operatorname{deg}_{v}\left(u_{i}\right)+v_{1}\left(u_{i}\right)=Q_{1}+c_{2} \operatorname{deg}_{\mu}\left[u_{j}\right]=\operatorname{deg}_{\mu}\left(u_{j}\right)+\mu_{1}\left(u_{j}\right)=P_{2}+c_{1}$ and $\operatorname{deg}_{v}\left\lfloor u_{j}\right\rfloor=\operatorname{deg}_{v}\left(u_{j}\right)+v_{1}\left(u_{j}\right)=Q_{2}+c_{2}$.

Claim: $\operatorname{deg}_{\mu}\left[u_{i}\right] \neq \operatorname{deg}_{\mu}\left[u_{j}\right]$ and $\operatorname{deg}_{v}\left[u_{i}\right] \neq \operatorname{deg}_{v}\left[u_{j}\right]$. Suppose that, $\operatorname{deg}_{\mu}\left[u_{i}\right]=\operatorname{deg}_{\mu}\left[u_{j}\right]$ and $\operatorname{deg}_{v}\left[u_{i}\right]=\operatorname{deg}_{v}\left[u_{j}\right]$. Consider $\operatorname{deg}_{\mu}\left[u_{i}\right]=\operatorname{deg}_{\mu}\left[u_{j}\right]$

$P_{1}+c_{1}=P_{2}+c_{1}$

$P_{1}-P_{2}=c_{1}-c_{1}=0$

$P_{1}=P_{2}$, which is a contradiction to $P_{1} \neq P_{2}$

Therefore, $\operatorname{deg}_{\mu}\left[u_{i}\right] \neq \operatorname{deg}_{\mu}\left[u_{j}\right]$. Similarly, we consider

$\operatorname{deg}_{v}\left[u_{i}\right]=\operatorname{deg}_{v}\left[u_{j}\right]$

$Q_{1}+c_{2}=Q_{2}+c_{2}$

$Q_{1}-Q_{2}=c_{2}-c_{2}=$ 。

$Q_{1}=Q_{2}$, which is a contradiction to $Q_{1} \neq Q_{2}$

Therefore, $\operatorname{deg}_{v}\left[u_{i}\right] \neq \operatorname{deg}_{v}\left[u_{j}\right]$. Hence, $G$ is a neighbourly totally irregular interval valued fuzzy graph.

\section{Application in social networks}

The social networks are the suitable examples of interval-valued fuzzy graphs. In such networks an account of individual or organization or a group of people is taken as node. If there is some relationship between the nodes then they are connected by an edge. In such networks, we assume that a node (i.e. a person, organization, etc.) has both (good) and (bad) activities. The degree of good activities and bad activities represent the good (within $[0,1]$ ) and bad (within $[0,1]$ ) membership values of a node. Similarly, the degree of relationship between the nodes measures the edge membership value. It may be observed that, two persons have good attitude for some types of activities (such as teaching method, student evaluation, etc.) and they also have bad mind some other types of activities (say political view, food habit, etc.). Thus, there are two types of edge membership values, viz. good and bad. This type of network is an ideal example of interval-valued fuzzy graph. An essential and difficult task in any social network is to find the central (global or local) person. A central person can spread any information to a large number of people quickly. The determination of central person is called centrality problem. Through such central person one (organization, industry, etc.) can broad cast their product information, news, etc. to the large number of people, keeping in mind good 


\section{New Concepts of Interval-Valued Fuzzy Graphs with Application}

and bad attitudes. Besides, the concept of interval-valued fuzzy graphs can be applied in various areas of engineering, computer science: database theory, expert systems, neural networks, artificial intelligence, signal processing, pattern recognition, robotics, computer networks, medical diagnosis etc.

\section{Conclusions}

It is well known that graphs are among the most ubiquitous models of both natural and human-made structure. They can be used to model many types of relations and process dynamics in computer science, physical, biological, and social systems. Many problems of practical interest can be represented by graphs. In this paper, the concepts of neighbourly irregular interval-valued fuzzy graphs, neighbourly totally irregular intervalvalued fuzzy graph, highly irregular interval-valued fuzzy graphs and highly totally irregular interval-valued fuzzy graphs are introduced and investigated. A necessary and sufficient condition under which neighbourly irregular and highly irregular intervalvalued fuzzy graphs are equivalent is discussed.

\section{REFERENCES}

1. M. Akram, Bipolar fuzzy graphs, Information Sci., 181 (2011) 5548-5564.

2. M. Akram, Interval-valued fuzzy line graphs, Neural Computing \& Applications, DOI:/10.1007/s00521-011-0733-0.

3. M. Akram, W.A. Dudek, Interval-valued fuzzy graphs, Computers Math. Appl., 61 (2011) 289-299.

4. P. Bhattacharya, Some remarks on fuzzy graphs, Pattern Recognition Letters, 6 (1987) 297-302.

5. K. R. Bhutani, A. Battou, On M-strong fuzzy graphs, Information Sci., 155 (2003) 103-109.

6. R. A Borzooei, H. Rashmanlou, Degree of vertices in vague graphs, Journal of Applied Mathematics and Informatics, 33 (50) (2015) 545-557.

7. R. A. Borzooei, H. Rashmanlou, Dominating in vague graph and its applications, Journal of Intelligent and Fuzzy Systems, 29 (5015) 1933-1940.

8. R. A. Borzooei, H. Rashmanlou, New concepts of vague graphs, International Journal of Machine Learning and Cybernetics, DOI 10.1007/s13042-015-0475-x.

9. R. A. Borzooei and H. Rashmanlou, More results on vague graphs, U.P.B. Sci. Bull., Series A, 78 (1) 2016) 109-122.

10. R. A. Borzooei and H. Rashmanlou, Semi global domination sets in vague graphs with application, Journal of Intelligent and Fuzzy Systems, 30 (2016) 3645-3652.

11. R. A. Borzooei, H. Rashmanlou, S. Samanta, M. Pal, Regularity of vague graphs, Journal of Intelligent and Fuzzy Systems, 30 (2016) 3681-3689.

12. R. A. Borzooei and H. Rashmanlou, Degree and total degree of edges in bipolar fuzzy graphs with application, Journal of Intelligent and Fuzzy Systems, 30 (2016) 3271328.

13. M. B. Gorzalczany, A method of inference in approximate reasoning based on interval-valued fuzzy sets, Fuzzy Sets Syst., 21 (1987) 1-17.

14. M. B. Gorzalczany, An interval-valued fuzzy inference method some basic properties, Fuzzy Sets Syst., 31 (1989), 243-251. 
Hossein Rashmanlou and Mostafa Nouri Jouybari

15. J. Hongmei, W. Lianhua, Interval-valued fuzzy subsemigroups and subgroups sssociated by intervalvalued suzzy graphs, 2009 WRI Global Congress on Intelligent Systems, 2009, 484-487.

16. M.Hota, M.Pal and T.K.Pal, An efficient algorithm for finding a maximum weight k-independent set on trapezoid graphs, Computational Optimization and Applications, 18 (1) (2001) 49-62.

17. M.Hota, M.Pal and T.K.Pal, An efficient algorithm to generate all maximal independent sets on trapezoid graphs, International Journal of Computer Mathematics, 70 (4) (1999) 587-599.

18. A. Kaufman, Introduction a la Theorie des Sous-emsembles Flous, Masson et Cie 1, 1973.

19. J. M. Mendel, Uncertain rule-based fuzzy logic systems: Introduction and new directions, Prentice-Hall, Upper Saddle River, New Jersey, 2001.

20. J. N. Mordeson, P. S. Nair, Fuzzy graphs and fuzzy hypergraphs, Physica Verlag, Heidelberg 1998; Second Edition 2001.

21. J. N. Mordeson, C. S. Peng, Operations on fuzzy graphs, Information Sci., 79 (1994), 159-170.

22. S.Mondal, M.Pal and T.K.Pal, An optimal algorithm for solving all-pairs shortest paths on trapezoid graphs, International Journal of Computational Engineering Science, 3 (2) (2002) 103-116

23. M. Pal and H. Rashmanlou, Irregular interval- valued fuzzy graphs, Annals of Pure and Applied Mathematics, 3 (1) (2013) 56-66.

24. M. K. Roy, R. Biswas, I-V fuzzy relations and Sanchez's approach for medical diagnosis, Fuzzy Sets Syst., 47 (1992), 35-38.

25. A. Rosenfeld, Fuzzy graphs, Fuzzy Sets and their Applications (L.A.Zadeh, K.S.Fu, M.Shimura, Eds.), Academic Press, New York, 1975, 77-95.

26. H. Rashmanlou and M. Pal, Antipodal interval-valued fuzzy graphs, International Journal of Applications of Fuzzy Sets and Artificial Intelligence, 3 ( 2013) 107-130.

27. H. Rashmanlou and M. Pal, Balanced interval-valued fuzzy graph, Journal of Physical Sciences, 17 (2013) 43-57.

28. H. Rashmanlou, S. Samanta, M. Pal and R. A. Borzooei, A study on bipolar fuzzy graphs, to appear in Journal of Intelligent and Fuzzy Systems.

29. H. Rashmanlou and Y. B. Jun, Complete interval-valued fuzzy graphs, Annals of Fuzzy Mathematics and Informatics, 6(3) (2013) 677-687.

30. H.Rashmanlou and M.Pal, Some properties of highly irregular interval valued fuzzy graphs, World Applied Sciences Journal, 27 (12) (2013) 1756-1773.

31. H.Rashmanlou and M.Pal, Isometry on interval-valued fuzzy graphs, International Journal of Fuzzy Mathematical Archive, 3 (2013) 28-35.

32. S. Samanta and M. Pal, Fuzzy tolerance graphs, Int. J Latest Trend Math, 1(2) (2011) 57-67.

33. S. Samanta, M. Pal and A. Pal, New concepts of fuzzy planar graph, International Journal of Advanced Research in Artificial Intelligence, 3(1) (2014) 52-59.

34. S. Samanta and M. Pal, Fuzzy k-competition graphs and p-competition fuzzy graphs, Fuzzy Engineering and Information, 5(2) (2013) 191-204.

35. S. Samanta and M. Pal, Irregular bipolar fuzzy graphs, Int J Appl Fuzzy Sets, 2 (2012) 91-102. 
New Concepts of Interval-Valued Fuzzy Graphs with Application

36. S. Samanta and M. Pal, Fuzzy threshold graphs, CiiT International Journal of Fuzzy Systems, 3(12) (2011) 360-364.

37. S.Samanta, M.Akram and M.Pal, m-Step fuzzy competition graphs, Journal of Applied Mathematics and Computing, 47 (1-2) (2015) 461-472.

38. S.Samanta and M.Pal, Fuzzy planar graphs, IEEE Transactions on Fuzzy Systems, 23 (6) (2015) 1936-1942.

39. A. Shannon and K.T. Atanassov, A first step to a theory of the intuitionistic fuzzy graphs, Proc. FUBEST (D. Lakov, Ed.), Sofia, 1994, 59-61.

40. L. A. Zadeh, Fuzzy sets, Information and Control, 8 (1965) 338-353.

41. L. A. Zadeh, Similarity relations and fuzzy orderings, Information Sci., 3 (1971) 177200.

42. L. A. Zadeh, The concept of a linguistic and application to approximate reasoning, Information Sci., 8(1975) 199-249.

43. M.Hota, M.Pal and T.K.Pal, An efficient algorithm for finding a maximum weight kindependent set on trapezoid graphs, Computational Optimization and Applications, 18 (1) (2001) 49-62.

44. M.Hota, M.Pal and T.K.Pal, An efficient algorithm to generate all maximal independent sets on trapezoid graphs, International Journal of Computer Mathematics, 70 (4) (1999) 587-599.

45. S.Mondal, M.Pal and T.K.Pal, An optimal algorithm for solving all-pairs shortest paths on trapezoid graphs, International Journal of Computational Engineering Science, 3 (2) (2002) 103-116. 